Vol. 5, No. 1, 2020

\title{
THE LIFE PATH AND SCIENTIFIC ACTIVITY OF PROFESSOR BEATA KOWALSKA
}

\author{
Dariusz Kowalski \\ Department of of Water Supply and Wastewater Disposal, \\ Faculty of Environmental Engineering, \\ Lublin University of Technology, \\ 40B Nadbystrzycka Str., Lublin, 20-618, Poland \\ d.kowalski@pollub.pl
}

https://doi.org/10.23939/ep2020.01.007

Received: 04.12.2019

(C) Kowalski D., 2020

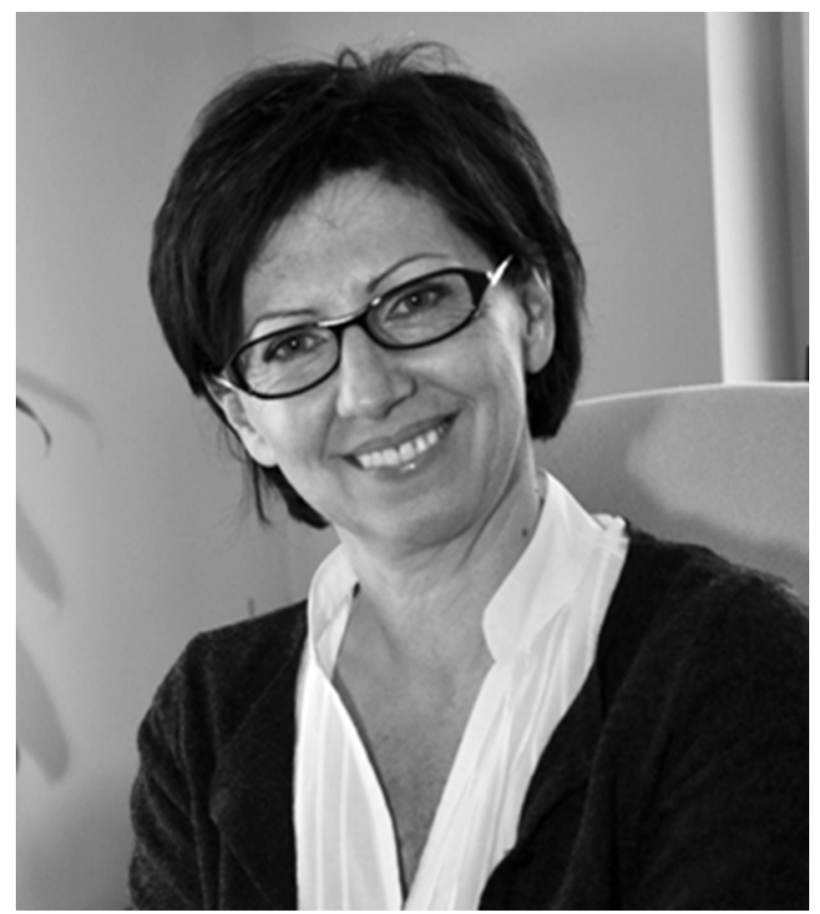

Abstract. In the article the main scientific activities and the main stages of the work of professor Beata Kowalska has been presented. The main scientific research embracing studies on the quality of potable water, studies aiming at devising the tools and methods facilitating water quality control in a water supply network, also studies aiming at devising the methods facilitating the operational activities, necessary for a correct functioning of water supply systems have been discussed.

Key words: water quality, water distribution system, monitoring, plastic pipes.
In 1984, Beata Kowalska graduated from the Faculty of Civil and Sanitary Engineering of Lublin University of Technology (scientific discipline: Environmental Engineering, specialty: thermal and sanitary equipment). In early 1985, she was employed in the Department of Heating and Ventilation at the Faculty of Civil and Sanitary Engineering of Lublin University of Technology as a junior assistant and a year later - as an assistant.

In that time, she began developing interests connected with heat transfer in new-generation engineering materials, which then included plastics (polymer materials). In the academic year 1992/1993, in order to expand her knowledge on the properties and structure of plastics and their processing, B. Kowalska participated with the consent of the director of the Department of Polymer Processing, professor Robert Sikora - in the classes held at the Faculty of Mechanical Engineering in the specialization "Polymer Processing". When the classes finished, B. Kowalska received a subject proposal for the doctoral dissertation, involving experimental research on the thermal properties of selected polymer materials. In 1995, she did a 6-month scientific internship in the Department of Polymer Processing. She was awarded the doctor in technical science degree in 1995, having successfully defended the dissertation entitled "Investigation of selected thermal properties of low density polyethylene" at the Faculty of Mechanical Engineering of University of Science and Technology in Bydgoszcz. In the years 1995-2008, she was employed as an assistant professor, initially at the Faculty of Civil and Sanitary Engineering and then at the Faculty of Environmental Engineering of Lublin University of Technology. She was awarded the habilitated doctor of technical science degree by the Faculty Council of Lublin 
University of Technology, on the basis of the monograph entitled "Processing aspects of thermodynamic properties characterizing thermoplastic polymers”. Since 2008, Beata Kowalska have been employed as an Associate Professor at the Faculty of Environmental Engineering in the Department of Water Supply and Wastewater Disposal. Apart from dealing with polymer materials in terms of their processing, her interest was also drawn to their application in designing the heating as well as water supply and sewerage systems.

In 1987, B. Kowalska served a three-month professional internship in the Institute of Physical Planning and Municipal Economy in Lublin. In the late 1987 to 1991 , she was additionally employed halt-time in the Historic Architecture Studio ABRYS LLC in Lublin as designer's assistant. Numerous contacts with water supply companies and design offices contributed to her growing interest in water supply and sewerage systems, especially in terms of water quality connected with the characteristics and properties of applied materials. Since 2018, B. Kowalska has also been employed as the main expert on mathematical models of water quality at the Department of Modern Technologies and Innovation in the Upper Silesian Water Supply Company in Katowice.

Prior to obtaining the habilitated doctor degree, her scientific interest mainly involved the issues connected with thermal technology, especially heat transfer in engineering materials. The main topic of her research pertained to the analysis of thermal properties of polymers and the influence of processing conditions on these properties. Prof. Beata Kowalska obtained the necessary funds by preparing a supervisor's grant KBN 419/T08/95/08 and the main aim of the research was to obtain polyethylene products which later constituted the material for determining thermal diffusivity, specific heat, index of thermal conductivity and crystallinity degree of samples. The work enabled to learn more about the selected thermal properties of polyethylene, i.e. a material commonly used in all aspects of life, including environmental engineering.

After obtaining the Doctor of Science degree, her interest in the issues related to heat transfer continued; prof. B. Kowalska also expanded her area of research. Her research works mainly included the studies on thermodynamic characteristic of thermoplastic polymers commonly used for the manufacturing of pipes, fittings and sanitary elements, studies on the structure of plastic products and the relationship between their manufacturing process and structure. Some of her research results were presented at international conferences organised by Polymer Processing Society - of which she was a member in 1995-2011 - in various countries around the world. Among the research on thermodynamic issues, the derivatives of thermodynamic equations of state of polymers, including the thermal expansion coefficient and coefficient of compressibility are essential in designing installation systems. The thermodynamic analysis of polymer materials and influence of injection conditions was the topic of her habilitation dissertation entitled "Processing aspects of thermodynamic properties characterizing thermoplastic polymers".

Main interest areas of prof. B. Kowalska also included the influence of additives, mainly flame retardants on the thermodynamic condition of plastics. These studies contributed to the development of her interests connected with the toxicity and the hazards resulting from the application of modifying agents introduced to polymers during processing. Prof. Kowalska developed this direction of research after obtaining the doctor at the Faculty of Environmental Engineering.

As part of her activity related with polymer materials in Environmental Engineering, she also developed an interest in the plastics used for pipe manufacturing, especially the impact of pipe material on the quality of tap water. In that period, prof. B. Kowalska was the main executive in the research Project entitled "Creation and propagation of pollutants in oversized water supply network" (KBN 1134/T09/2003/24), implemented in the Department of Water Supply and Sewerage at the Faculty of Environmental Engineering of Lublin University of Technology, headed by prof. Dariusz Kowalski.

While investigating the issue of deformation in polyethylene pipes with different wall structure, prof. Kowalska devised the plan and research methodology as well as supervised the construction of laboratory installation for studying the deformation of thermoplastic pipes laid in soil, which was built at the Faculty of Civil and Sanitary Engineering of Lublin University of Technology. Correct strength tests of the reciprocal effect within the pipe-soil system, accounting for the rheological properties, is of great importance in designing gravitational water supply network using thermoplastics. The studies on the deformation of polyethylene pipes with different wall structure were commissioned by ArotPolska LLC company.

Having been awarded the habilitated doctor degree, prof. Beata Kowalska used her experience acquired over years of cooperation with the Department of Polymer Processing at the Faculty of Mechanical Engineering of Lublin University of Technology, as well as the experience from the implementation of the research project connected with the generation and propagation of pollutants oversized water supply network, which led to the idea of creating own research tools and forming a research team at the Faculty of Environmental 
Engineering. She began conducting scientific and research works, which can be classified into several categories:

- Studies on the quality of water in its distribution system, identifying the phenomena influencing its secondary contamination, especially in terms of the impact of applied materials on the quality of water in contact with them.

- $\quad$ Studies aiming at devising the tools and methods facilitating water quality control in a water supply network, devising the methodology for monitoring the water quality, use of computer tools for simulating changes in the quality of water during its transportation.

- Identifying the hydraulic flow conditions in pressure pipes, application of tools for simulating changes in the rate and pressure in complex structures such as water supply networks.

- Studies aiming at devising the methods facilitating the operational activities, necessary for a correct functioning of water supply systems.

In order to perform the task connected with the research on water quality in its distribution system, especially in the terms of the impact of applied materials on the quality of water in contact with them, she devised the plan and research methodology and supervised the construction of a laboratory installation for conducting qualitative studies. The installation was constructed at the Faculty of Environmental Engineering in the Laboratory of Applied Hydraulics. Thus prepared set-up enabled to carry out first, pilot studies in line with the assumed schedule. Basic physicochemical properties of water and organic compounds leached from pipes were determined during the investigations. The tests were carried out using Thermo Trace GC Ultra multichannel gas chromatograph coupled with Polaris Q mass spectrometer, which was available at the Faculty of Environmental Engineering of Lublin University of Technology. Initial analyses indicated the presence of organotin compounds in the water from PVC-U pipes that were part of stabilisers used for the pipe manufacturing process. The obtained research results were presented at conferences and published in ranked journals; they constituted the basis for applying for a research project related to this subject. The funding application for the research project "Impact of pipe material on the quality of tap water”) was prepared and submitted in July 2008. Funding was granted in 2009 and a team led by prof. Kowalska started its implementation (Research project 4508/B/T02/2009/36, 2009-2012). The acquired knowledge on plastic processing, combined with the specificity of water supply system operation, enabled a comprehensive approach to the analyzed issues. The tests were carried out not only at laboratory scale, but also on actual water supply networks in the Lubelskie Voivodeship. Tests were conducted on two laboratory installations assembled using pipes from unplastified polyvinyl chloride (PVC-U), high density polyethylene (PE-HD) and crosslinked polyethylene (PEX), operating in closed circuit. The installations were located at the Faculty of Environmental Engineering, in the Laboratory of Applied Hydraulics.

As part of grant implementation, prof. Kowalska established the cooperation with Municipal Water and Sewerage Company in Puławy. A second research installation, operating in a flow system, assembled using PVC-U, PE-HD and ductile cast-iron, was created in the main pumping station building in Puławy. In the academic year 2008/2009, her team conducted the measurements of the impact of $3.5 \mathrm{~km}$ long polyethylene pipe - which constituted a fragment of the water supply network in Puławy - on the quality of transported water.

The studies conducted on laboratory installations pertained to the material-related influence of polyethylene and PVC pipes on the quality of water, both in the chemical and microbiological aspects. The identified chemical compounds leached from plastic pipes were mainly attributed to the anti-oxidants - added in the pipe manufacturing process - as well as their derivatives or degradation products. The results were published in international journals [e.g. 1-4], as monograph chapters [e.g. 5, 6]; they were also presented at national and international conferences [e.g. 7]. The loss of biological stability of water in water supply systems is strictly connected with the growth of biofilms on pipe walls. Plastic pipes are resistant to corrosion; however, biofilms can still appear. The biofilm formation on pipe walls depends both from the pipe material, as well as the quality of water, its flowrate and the applied disinfectants. The microbiological studies connected with the susceptibility of pipes to biofilm growth were only conducted under laboratory conditions due to the difficulties in collecting the material for study from an actual water supply network. The obtained results were published in an international journal [8], a Polish journal and as a monograph chapter. As part or project implementation, the influence of selected plastic pipes on the organoleptic properties of water in contact with them was analyzed as well. The results of these studies were published in a Polish journal that is indexed in JCR.

Simultaneously to the laboratory studies that focused on chemical and microbiological analyses, prof. Kowalska was interested in modelling the migration of pollutants in plastic pipes was made using state-of-the-art computer tool, i.e. Ansys - Fluent software. The software was purchased using the funds for the realization of a 
research project and was used for conducting novel model studies connected with leaching and propagation of pollutants from plastic pipes in the transported water. The obtained results were published in international and Polish journals [e.g. 9, 10]. These pilot studies were developed in the course of later studies that constituted the basis for doctoral dissertation of Anna Musz, which Prof. Kowalska supervised. In addition to the qualitative analysis of water from plastic pipes, their mechanical properties and resistance to water disinfectants such as chlorine compounds were assessed as well. Apart from the plastics used for pipe production, ductile cast iron pipes have recently become popular as well, especially in the cases where the designed network is created in the locations characterised by significant road traffic. Therefore, new ductile cast iron pipes were added to the existing plastic pipe installation assembled on the premises of a pumping station in Puławy. The results of studies on the water in contact with cement lining, covering the inner surface of cast iron pipes, were published in international journal [11]. Years of prof. Kowalska effort devoted to studying polymer materials were summarised through publication of a monograph entitled "Material-Related Impact of Thermoplastic Pipes on Quality of Distributed Water" by the Polish Academy of Sciences in Monographs of the Environmental Engineering Committee Series [12]. In the work, she presented the basic information pertaining to polymers, polymer materials and commercial products, i.e. pipes, presenting the details of material engineering and polymer processing, which are seldom disclosed by pipe producers and therefore poorly known in sanitary engineering. The monograph presented characteristics of materials, degradation and destruction processes of polymers as well as modifying agents added in the course of pipe manufacturing process. The work also characterised the current legal regulations, both Polish and international, related to the material of pipes in contact with the water intended for human consumption. The data are used as reference in the further part of the monograph, showing the results of field and laboratory studies. Prof. Kowalska presented the groups of pollutants that may infiltrate into water as a result of its contact with thermoplastic pipes. As far as the safety of water recipients is concerned, the knowledge on the issues concerning migration of pollutants from pipe material to water as well as the interactions between these substances and growth of microorganisms is extremely important. The application of computer fluid mechanics (CFD) for determining the effect of pipe material on the quality of transmitted water was presented on the example of a simulation involving leaching and propagation of BHT (Butylated Hydroxytoluene) antioxidant, commonly employed for the production of polyethylene pipes. Simulation calculations can be an alternative to tedious laboratory and field studies, while the employed tool enables determining the impact of different pollutants originating from pipe material on the quality of water. The approach presented in the work is rarely taken in the available publications. Apart from the presented own research results, the monograph contains numerous references to the studies published by other scholars, mainly foreign, because there are few Polish reports pertaining to this subject. Such an approach, in addition to the interpretation of results, enables a simultaneous evaluation of the progress of works in Poland and worldwide, in terms of the impact of pipe material on the quality of transported water.

Summing up this most important research area of the scientific activity of Prof. Beata Kowalska, the original achievements constituting a significant contribution to the development of technical sciences include: a) identification of a group of pollutants that may appear in water as a result of its contact with thermoplastic pipes, b) identification of the mechanisms characterizing chemical compounds migration from polymer pipe material to tap water; attempt at devising the tools enabling predicting the changes in the concentration of chemical and microbiological substances in the water flowing through plastic pipes, c) application of numerical methods and commercial computer software for simulating the leaching of anti-oxidants from pipe material and their propagation in the water flowing through plastic pipes, d) devising an original method of chromatographic analysis pertaining to the anti-oxidant concentration in plastics, combining size-exclusion chromatography $(S E C)$ with gas chromatography-mass spectrometry $(G S-M C)$, e) constructing a laboratory installation for dynamic water flow investigations, simulating actual water supply network operation conditions, f) conducting similar analyses in fragments of existing water supply networks, $g$ ) indicating that there is no control over the chemical composition of pipes is carried out on the production line, h) drawing attention to the fact that the pipe samples provided for quality control prior to their application in water transport installations are non-representative, i) indicating the poverty of research on the type and magnitude of the detrimental effect exerted by modifying agents introduced to polymers during the plastic pipe manufacturing process as well as signaling the need of conducting such research in order to create a list of these substances and supplement it with appropriate legal regulations.

Continuing the work connected with the quality of water in the distribution system, along with her team, 
prof. Kowalska embarked on the studies aiming at devising the tools and methods facilitating the control over the quality of water in a water supply network, devising the methodology for water quality monitoring, use of computer tools for simulating changes in water quality during its transport. Due to the problems connected with the quality of water reported by water and sewerage companies, these studies involved both field studies as well as simulations performed using computer software such as Epanet 2.0, Aquis or WaterGems, enabling simulating changes in the quality of water quality in a water supply network. Such simulations also facilitate the decision making process while expanding or modernizing systems. The publications on the tools for water quality modelling in distribution systems were published in international and Polish journals [13-16]. Computer software may also be helpful in devising the methods of selecting the locations for monitoring the quality of water or other system operation parameters. This is a difficult task, because there are numerous factors influencing the changes in water quality in a distribution system; additionally, the multitude and complexity of the existing water supply networks make the matter even worse. There is a plethora of water quality monitoring methods available worldwide; however, none of them is universal. Prof. Kowalska research team conducted the studies which attempted at devising new methods. The obtained results were published in the Polish Academy Of Sciences journal [17]. A new method for water quality monitoring was devised as part of the Ph.D. dissertation which prof. Kowalska supervises.

While analyzing the water quality in actual water distribution systems, it is necessary to account for a number of parameters influencing changes in water quality during its transport to a recipient. These studies were conducted with significant contribution of prof. B. Kowalska, and aimed at identifying the hydraulic flow conditions in pressure pipes, application of tools for simulating the changes in rate and pressure in water supply networks. Identification of hydraulic conditions of water supply system operation constitutes the basis for the correct assessment of water quality and building qualitative models. It may also be used for monitoring hydraulic parameters such as pressure or flow intensity, necessary for correct management of a water supply or sewerage network. Some of the analyses were conducted as a preparatory stage for the creation of numerical water quality models. Some of them were prepared independently, often with the cooperation of water supply companies.

The area of research aiming at devising the methods aiding in operation, necessary for the correct functioning of water supply systems stemmed predominantly from her numerous contacts with water supply and sewerage companies, established within the last 10 years. Currently, exploitation activities are top priority in these companies due to the ageing infrastructure and increasingly stringent requirements pertaining to the quality of water supplied to recipients. Despite the availability of modern diagnostic equipment, there is still as lack of universal methods or tools facilitating the operation and ensuring the safety of water supply. Variable hydraulic conditions, including failures, may significantly hinder the network operation and result in financial losses. This topic was explored in numerous publications that included her substantial contribution and resulted from specific requirements or arising problems. The issues connected with the failure rate of water supply and sewerage infrastructure elements were published in international and Polish journals [e.g. 18, 19].

As far as the exploitation problems faced by water supply companies are concerned, prof. B. Kowalska also dealt with the analysis of water losses it the distribution system as well as evaluation of the reliability of its supply. This research was conducted on existing objects, while the results were published in international journals and as monograph chapters [e.g. 20, 21, 22].

Several works, written under her supervision, pertained to exploitation issues of sewerage systems, including non-conventional ones such as small diameter sewerage. In addition to a work that constituted expert's opinion for the needs of a commune. A significant area of her scientific activity was aimed at practical application. Prof. Kowalska is a co-author of $\mathbf{1 8}$ patented inventions, 1 utility model with protection right, $\mathbf{6}$ patent applications Six inventions and one utility model were presented at international fairs, receiving medals and recognition.

Prof. Kowalska cooperates with scientific units, manufacturing companies, as well as water supply and municipal companies. The main scientific centres she constantly collaborate with include Division of Water Supply and Wastewater Treatment of Warsaw University of Technology and Faculty of Mechanical Engineering of Lublin University of Technology. In 2018, prof. Kowalska served a scientific internship in the Department of Polymer Processing of Institute of Mechanical Technologies at the Faculty of Mechanical Engineering and Computer Science of Częstochowa University of Technology. The internship was connected with such areas as environmental aspects of polymer recycling, technologies of polymer material recycling, recycling of multi-material polymer products.

As far as the international activity is concerned, prof. Kowalska mainly cooperates with scientific institutes and universities. Since 2012, she has cooperated with prof. 
Henryk Sobczuk of Polish Academy of Sciences, Scientific Center in Kiev and Lviv Polytechnic National University. This collaboration resulted in joint organization of cyclic international conferences "Pure Water. Fundamental, Applied and Industrial Aspects" in Kiev and "Water supply and wastewater removal: designing, construction, operation and monitoring" organised at Lviv Polytechnic National University. Since 2014, prof. Beata Kowalska has also cooperated with Wessex Institute (Great Britain) and Polytechnic University of Milan (Italy). She participates in the works of the scientific committee of conferences that take place every two years in different European countries. Initially, this conference - URBAN WATER - was later re-named as FRIAR. She also embarked on the cooperation with Technical University of Kosice, Faculty of Mechanical Engineering/Institute of Technologies and Management Department of Technologies and Materials in Slovakia, where she served 2 short-term internships. They were mainly connected with the education of doctoral students.

Since 2018 prof. B. Kowalska has been a leader of a statutory research task "Safety of water supply and wastewater disposal", implemented at the Faculty of Environmental Engineering and Department, in Department of Water Supply and Wastewater Disposal. In 2017 she was also an external expert working during the preparation and proceeding of public procurement for "Development of mathematical models for water quality prediction and risk management algorithm as part of the research and development works for the creation of a smart system for risk management in a water supply company and production of water quality intended for human consumption" task, submitted by Upper Silesian Water Supply Company in Katowice, contract no. ZTK/38/2017. Moreover, she was elected a deputy chairperson in the tender board appointed by Upper Silesian Water Supply Company in Katowice. Since October 2018, she has been the chief expert on mathematical models of water quality in the Department of Modern Technologies and Innovation in Upper Silesian Water Supply Company in Katowice.

As part of the popular science activity, apart from delivering presentations at the events promoting the University and Faculty, prof. Kowalska published science-promoting papers for a broad audience, also delivered numerous lectures at the invitation of various institutions. They include the inaugural lecture "Modern polymer materials" delivered in 2008 during the $55^{\text {th }}$ anniversary of Lublin University of Technology, as well as a lecture "Characteristics of plastic pipes" delivered abroad on April 17, 2013 at the University of Rivne in Ukraine, a lecture at the invitation of Polish Academy of Sciences, delivered at the session of Section of Sanitary
Engineering of Civil Engineering and Hydroengineering Committee of the Polish Academy of Sciences, as well as a lecture at the invitation of Municipal Water and Sewerage Company in Lublin and 2 lectures delivered at trainings.

Prof. Beata Kowalska is an active member of University and Faculty committees as well as organizations that collaborate with and international research units (which includes the social, regional and state activities). Since 2016, she is a member of the Staff Disciplinary Appeals Committee in Lublin University of Technology, for 10 years she has been a disciplinary spokesperson for academic teachers. In 1995-2011 she was a member of "Polymer Processing Society", an international association of scientists mainly dealing with processing, properties and application of polymer materials. Since 2007, she has been a member of Sanitary Engineering subsection of Division IV of Polish Academy of Sciences and since 2008 - a member of Polish Association of Sanitary Engineers and Technicians in which she is an expert on the specialty: water supply and sewerage: networks, objects, devices and installations in research and study works.

\section{References}

[1] Kowalska B., Kowalski D., Rożej A.: J. Water Supply Research and Technol., AQUA, 2011,60, 137.

[2] Musz-Pomorska A., Widomski M., Kowalska B.: Envir. Protection Eng., 2015, 41, 5.

[3] Kowalska B., Kowalski D., Kwietniewski M., Musz A.: J. Sustain. Develop., 2013,6,2.

[4] Musz A., Kowalska B., Widomski M. K.: Ecol. Chem. and Eng. S, 2009, 16, 175.

[5] Kowalska B., Kowalski D., Suchorab P., Iwanek M.: Secondary water contamination in selected rural supply network [in:] I. Zimoch (Ed.), Current issues in water treatment and water distribution. Politechnika Śląska, Gliwice 2016, 161-172.

[6] Kowalska B., Kowalski D., Suchorab P., Iwanek M.: Water quality analysis in a selected rural water supply system [in:] H. Sobczuk, B. Kowalska (Ed.), Water supply and wastewater removal. Monographs. Lublin University of Technology 2016, 95-106.

[7] Kowalski D., Kowalska B.: 11th International Conference on Computing and Control for the Water Industry: "Urban Water Management - Challenges and Opportunities", University of Exeter, United Kingdom, 2011.

[8] Rożej A., Cydzik-Kwiatkowska A., Kowalska B., Kowalski D.: World Journal of Microb. \& Biotech., 2015,31, 37.

[9] Musz-Pomorska A. Kowalska B.: Ecol. Chem. And Eng. S, 2015, 22, 219.

[10] Widomski M., Kowalska B., Musz-Pomorska A.: Process. of Ecopole, 2011, 5, 467. 
[11] Wąsowski J., Kowalski D., Kowalska B., Kwietniewski M., Zaliwska M.: Applied Sci.-Basel, 2019, 9(7), 1348.

[12] Kowalska B.: Polish Academy of Sciences in Monographs of the Envir. Eng. Committee Ser. Warsaw 2019, 158 .

[13] Kowalska B., Musz A., Kowalski D.: Polish Journal of Envir. Studies, 2009, 18, 169.

[14] Kowalski D., Kowalska B., Hołota E., Choma A.: Ecol. Chem. And Eng. S, 2015, 22, 401.

[15] Musz A., Kowalska B., Widomski M. K.: Ecol. Chem. and Eng. S, 2009, 16, 175.

[16] Widomski M., Kowalska B., Musz-Pomorska A.: Process. of Ecopole, 2011, 5, 467.

[17] Kowalski D., Kowalska B., Kwietniewski M.: Bulletin of The Polish Academy Of Sci.-Tech. Sci., 2015, 63, 155. Iwanek M., Kowalska B., Hawryluk E., Kondraciuk K.: Maintenance and Reliability, 2016, 18, 278.
[20] Suchorab P., Kowalska B., Kowalski D.: Rocznik Ochrona Środowiska, 2016, 18, 416.

[21] Kowalski D., Kowalska B., Bławucki T., Suchorab P., Gaska K.: Water,2019, 11, 480.

[22] Kowalski D., Kowalska B., Kuzioła E., Suchorab P., Iwanek M.: The assessment of the degree of water sources diversification as a part of the water system safety audit. In: Sobczuk H., Kowalska B. (Ed.), Water supply and wastewater disposal. Monographs. Lublin University of Technol. 2018, 75-83.

[23] Kowalski D., Kowalska B., Suchorab P., Iwanek M.: Proposition of fractal dimension application for the estimation of certainty of water delivery [in:] Hernández S., Mambretti S., Proverbs D., Puertas J.(Ed.), Transactions on The Built Envir. Vol. 184. Urban water systems \& floods II, Southampton, Boston, UK: WIT Press 2018, 5-25. 